\title{
Situational Cognition of College English Education Based on Image Block Gain Optimization in Pseudo-haze State
}

\author{
https://doi.org/10.3991/ijet.v14i18.11183 \\ Hongli Lou \\ Henan Polytechnic University, Jiaozuo, China \\ mai17720136@163.com
}

\begin{abstract}
Situational cognition can help students to construct their knowledge to a great extent. In order to solve the problem of lack of situational cognition in College English teaching, this paper studies the validity of students' situational cognition in College English teaching based on the method of image block gain optimization. First, this paper analyses the general situation of situational cognition capacity in College English teaching in China at present, and puts forward the function of device image in constructing situational cognitive competence in teaching. Then, it divides device image into blocks under pseudo-haze conditions, and proposes the optimization method of block gain. Finally, on the basis of block gain, it makes an empirical test of situational cognitive competence in College English teaching. The empirical results show that image block gain optimization can effectively improve the construction of situational cognition capacity in College English teaching. With the help of this study, some new and useful ideas can be traced for the development of computer science and college English teaching, and also stimulate the further improvement of College English education in China.
\end{abstract}

Keywords-College English, situational cognition, block gain, pseudo mist, optimization

\section{Introduction}

The surge of information technologies has ushered the higher education in a new era of innovative and technologic information-based teaching model, thus making sure the college teachers integrate the information technologies represented by multimedia with situational cognition theory when designing pedagogical activities, in order to help students to better self-construct knowledge, and make these activities more efficient and practical.

Many experts at home focus more on the study and analysis of English education information. Some scholars have argued in the study of higher English teaching that the way the situational cognition of students gets improved is to use the multimedia and other technologies for situational creation [1]. Guan et al. [2] states that in the higher English education, it is required to concern reasonable application of multimedia technology, and the situation should fit with the teaching content when the infor- 
mational means is applied to create the situations. It is proposed by Wall that a real language world can be created by means of traditional teaching tools including wall maps and training aids, in addition to the information technologies that have been prevalent for creating the situations [3]. In the context of audiovisual and listening combination, the students' learning initiative will be maximized. In view of the importance of the international video in English teaching, Compton [4] proposes that among various methods for creating teaching situations more suitable for native language environment, videos may be more effective for creating situations due to its intuitiveness and audiovisuality.

With the multimedia technologies represented by video application, classroom video recording has become an important representation of current education information [5]. In the actual recording process, however, due to the lack of recording environment and equipment, the recorded videos have played a negative effect on students' development for situational cognition of teaching application. In addition, the teaching image enhancement has a more important application value [6-7]. There are many studies that focus on the image enhancement, such as contrast-limited histogram equalization algorithm [8], Retinex algorithm based on human visual system [9]. Jonson et al. [10] also raises a multi-scale algorithm for improving the Retinex algorithm; He et al. [11] suggests a dark channel prior method, etc., that provides an effective solution for optimizing video definition.

Based on the image block gain optimization, this paper examines the students' situational cognition capacity in college English teaching. First, we analyze the situational cognition profile in college English teaching at the present stage, and present what's the effect of equipment image on the teaching situation cognition construction; then divide the equipment image in pseudo-mist state into blocks, and propose the block gain optimization method; finally, based on the image block gain, we empirically test the situational cognition of college English teaching [12-25].

\section{Analysis of Image Block Gain Optimization Technology in Pseudo-Mist State}

\subsection{Overview of algorithm process}

When performing the enhancement on image blocks, the process of main algorithm is underlying as shown in Figure 1.

As shown in Figure 1, it is found that the gain factor optimization has an important effect on the final image. Therefore, based on the study of the image block gain optimization technology in the pseudo-mist state, the focus is on the gain factor to construct the most optimized image block enhancement. 


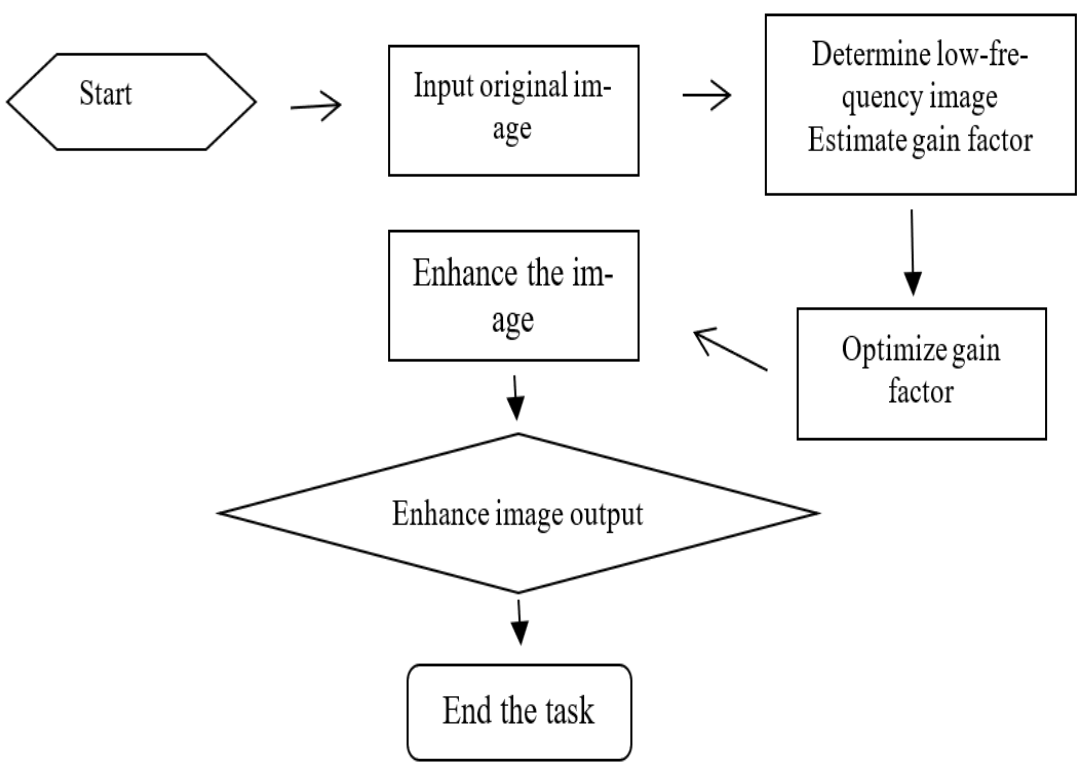

Fig. 1. Algorithm process

\subsection{Local contrast enhancement model based on unsharp mask}

In the local contrast enhancement for existing images, unsharp mask is a more common image processing model, where the enhanced model for the image is given as follows:

$$
S=P+C(P-A)
$$

where, $\mathrm{S}$ is the set of enhanced images, $S=\left\{s_{1}, s_{2}, \ldots, S_{n}\right\}$, where A is the component of the source image $P$ at the constant frequency, $A=\left\{a_{1}, a_{2}, \ldots, a_{n}\right\}$, then the image is composed of low and high frequency components, $\mathrm{P}-\mathrm{A}$ is the component of the original image at the high frequency. $\boldsymbol{C}$ is the gain factor for local contrast enhancement of the image.

Combining the Equation (1), it can be found that when the gain factor $C$ is a positive number, the enhancement effect is available when the image $P$ is processed. The Equation (1) is processed to obtain the Equation (2)

$$
P=\frac{1}{1+C} S+\left(1-\frac{1}{1+C}\right) A
$$

According to the image degradation model specification, when $\frac{1}{1+c}$ is included in $(0,1)$ interval, Equation (2) is designed as required by the image degradation model.

However, it should be noted that, on the whole, there is a certain gap in the image information between different areas, which makes the partial image enhancement effect different when enhancing, as shown in Equation (2), even if the gain factor is 
equal. Some image enhancement in some areas either does not measure up to a standard, or is overdone to lead the image information to missing.

In summary, it is unlikely to adopt the constant gain fact for image enhancement when constructing the model, but gain factor should be set as required for different areas, thereby reaching the optimization on partial image enhancement. For an image block $M$ required to be enhanced, the enhancement processing model is:

$$
S_{M}=\frac{1}{T}\left(P_{M}-A_{M}\right)+A_{M}
$$

As shown in Equation (3), when the enhancement is performed for the target image block, and the gain factor is set based on different areas, the contrast of the image block decreases as the value $\mathrm{T}$ increases during image enhancement. Therefore, it is required to pre-estimate the value $T$ to determine the optimal value when performing image enhancement according to Equation (3), thereby ensuring that the resultant image block can maintain the maximum image contrast effect.

\subsection{Enhancement factor optimization}

As above, in the contrast process model setting of the color image, after the contrast of the RGB channels included in the color image is summed, it can be found that the contrast of the color image is the decrement function relevant to $T$, as shown in Equation (4).

$$
E_{c}=\sum_{C o l \in(R, G, B)} \sum_{i \in M} \frac{\left(P_{M}^{C o l}(i)-\overline{P_{M}^{C o l}}\right)^{2}}{T^{2} k}
$$

As shown in Equation (3), the maximum image contrast generates in the case that the value $\mathrm{T}$ is the minimum. To ensure that the enhancement is not overdone to make the image pixel run overt and image information lose, the value $\mathrm{T}$ should be constrained and the appropriate constraints are true.

Based on the above analysis, the value $\mathrm{T}$ optimization model is processed to obtain the optimal value T calculation, as shown in Equation (5).

$$
T_{\max }=\max \left\{\min _{C o l \in(R, G, B)} \min _{i \in M}\left\{\frac{p_{M}^{C o l}(i)-A_{M}^{C o l}}{-A_{M}^{C o l}}\right\}, \max _{C o l \in(R, G, B)} \max _{i \in M}\left\{\frac{p_{M}^{C o l}(i)-A_{M}^{C o l}}{255-A_{M}^{C o l}}\right\}\right\}
$$

It can be found from Equation (5) that, based on the optimal value $T$, the optimal gain factor for different image blocks can be available, and in the case when the gain factor is determined, the associated image block is enhanced to ensure that enhancements are processed in an optimal state.

In this process mode, although the gain factor is determined for the image block, the enhancement with general gain factor used originally in the image block is still different since there is a difference between the pixels that constitute image block. Especially when the image mode includes the marginal information type whose pixel 
will change most obviously, it is most likely for the standardized gain factor to cause the incomplete performance of the marginal information, so that the available information cannot be fully represented.

In order to further achieve the optimization of gain factor, this paper will further optimize the gain factor to construct an optimal image block enhancement algorithm model.

To optimize the algorithm, the guided filtering mode will be introduced to achieve further optimization for gain factor. In this mode, the pixels in the image block move with the filtering window, so that the pixel $i$ in the image block exists in multiple windows. The pixel $l$ in different windows takes different values, so does $\bar{T}_{(i)}$ relevant to gain factor under this effect.

To solve this problem, it is required to perform the variance treatment on the pixel values contained in the image block, and use the minimum variance as the optimal criterion for selecting windows, to evaluate $\bar{T}_{(i)}$. It should also be noted that if there are multiple minimum variances, they should be averaged to determine the appropriate values, in order to obtain the optimal assignment model for the value $\mathrm{T}$, as shown in Equation (6).

$$
\bar{T}(i)=\bar{\alpha}_{i} I(i)+\bar{\beta}_{i}
$$

where, $\alpha_{i}$ is the color value of the color image; $\beta_{i}$ is an offset.

The T-optimal model determined by the Equation (6) is substituted into (3), to enhance the target image. On the other hand, according to the image enhancement principle, it is found when the value $\mathrm{T}$ tends to zero, the original image at this time is more often in a relatively fuzzy low-frequency state, and according to the algorithm such as He, we can further infer that when the gain factor is lower, a distant phenomenon that magnifies the noise of the original image will appear.

Combined with the above analysis, in the optimized image processing model, the gain factor is subjected to the lower limit constraint processing, and the lower limit $\mathrm{T}_{\mathrm{O}}$ takes 0.1 , so that the optimal image block enhancement algorithm model is available, as shown in Equation (7).

$$
S_{M}=\left(P_{M}-A_{M}\right) / \max \left\{\bar{T}(i), T_{O}\right\}+A_{M}
$$

where $\bar{T}_{(i)}$ is the optimized gain factor.

\subsection{Validity check of algorithm}

To check the validity of the algorithm herein, two video sample images are chosen and compared with different algorithms, see Table 1 . The results show that the image block gain optimization algorithm based on the pseudo-mist state renders better color retention and contrast enhancement for the image while reaching the defogging effect, moderate brightness and easy to view and other visual experience. 
The proposed algorithm is compared to the Retinex and He qualitatively and quantitatively. The results show that this algorithm renders a better global illumination effect can be achieved while defogging with the enhancement, and better color retention and image contrast enhancement than the other two algorithms, in addition to the moderate enhancement effect suitable for observation.

Table 1. Evaluation indicators for sample teaching video image enhancement

\begin{tabular}{|l|c|c|c|c|}
\hline \multirow{2}{*}{ Test Indicator } & \multicolumn{4}{|c|}{ Video image sample1 } \\
\cline { 2 - 5 } & Original image & Proposed algorithm & $\boldsymbol{H} \boldsymbol{M}$ & $\boldsymbol{M C}$ \\
\hline Mean & 114.5347 & 137.4214 & 138.6354 & 137.3148 \\
\hline Definition & 0.1762 & 0.4653 & 0.4832 & 0.6235 \\
\hline $\begin{array}{l}\text { Mean of neighbor } \\
\text { stan. devi. }\end{array}$ & 8.7638 & 26.6738 & 25.2374 & 28.7629 \\
\hline \multirow{4}{*}{ Test Indicator } & \multicolumn{4}{|c|}{ Video image sample2 } \\
\cline { 2 - 5 } & Original image & Proposed algorithm & $\boldsymbol{H} \boldsymbol{M}$ & $\boldsymbol{M C}$ \\
\hline Mean & 124.3753 & 141.1762 & 139.0163 & 138.2572 \\
\hline $\begin{array}{l}\text { Definition } \\
\text { Mean of neighbor } \\
\text { stan. devi. }\end{array}$ & 0.1762 & 0.4344 & 0.4754 & 0.5838 \\
\hline
\end{tabular}

\section{Analysis of Situational Cognition capacity of College English Education under Image Block Gain Optimization}

\subsection{Test results from optimal comparison}

In order to better test how the situational cognition of college English education is subject to the image optimization in the video teaching mode of image block gain optimization algorithm, college sophomore students in the English major are chosen to participate in the test. The optimized and regular video images are used, respectively. In order to ensure the scientific and effective results, in the specific composition of sample students, a basic course performance comparison is conducted among 60 students from each class. The average scores as tested is shown in Table 2.

Table 2. Score comparison between sample students

\begin{tabular}{|c|c|c|c|c|c|}
\hline \multirow{2}{*}{\multicolumn{2}{|c|}{ Comparison dimension }} & \multirow{2}{*}{\begin{tabular}{|c|} 
Opti. group \\
$\begin{array}{c}\text { Mean (standard devia- } \\
\text { tion) }\end{array}$ \\
\end{tabular}} & \multirow{2}{*}{\begin{tabular}{|c|} 
Control group \\
$\begin{array}{c}\text { Mean (standard devia- } \\
\text { tion) }\end{array}$ \\
\end{tabular}} & \multicolumn{2}{|c|}{$\begin{array}{c}\text { Independent sample T- } \\
\text { TEST }\end{array}$} \\
\hline & & & & $T$ & Sig \\
\hline \multirow{2}{*}{ Average score } & Before test & $62.14(15.47)$ & $61.97(16.13)$ & 0.139 & 0.879 \\
\hline & After test & $73.42(9.36)$ & $65.73(13.18)$ & 3.178 & 0.001 \\
\hline
\end{tabular}

It can be seen from the test scores that the scores of the optimization and control groups participating in the test are basically equal before the test, and there is no significant difference in the scores of the basic English course (Sig.=0.879). After the test, the optimization group has a mean score significantly different from the control group (Sig.=0.001), and higher than the latter. 
It is thus obvious that after video image data processed by the image block optimization algorithm is adopted by the optimization group, the scores of the sample students in the basic English course are greatly improved when compared with control group, suggesting that the image block gain optimization contributes to good English teaching results in colleges and universities.

\subsection{Investigation analysis of situational cognition of college English education under image block gain optimization}

Combined with sample test results and the analysis of the situational cognition capacity of English education, this paper decomposes the students' situational cognition of English and divides it into three dimensions: situational understanding, classroom interaction and self-construction. The content of the survey item is also designed to compare students' situational cognition by the results of the two groups of control samples.

Situational understanding: In the analysis of students' situational understanding, the project indicators are refined, and the analysis contents are set to 4 indicators, i.e. Q1 (English situation understanding), Q2 (English knowledge construction), Q3 (English situation simulation), Q4 (English situation application), the independent sample $\mathrm{T}$ test results of the students' situational understanding dimension control sample are shown in Table 3.

Table 3. Comparison in students' situational understanding dimension

\begin{tabular}{|l|c|c|c|c|c|}
\hline \multirow{2}{*}{ Dimension content } & \multirow{2}{*}{ Indicator } & Control group & Opti. group & \multicolumn{2}{c|}{ T-TEST } \\
\cline { 2 - 6 } & & Mean & Mean & T-value & Sig \\
\hline \multirow{3}{*}{$\begin{array}{l}\text { Students' situational under- } \\
\text { standing }\end{array}$} & Q1 & 3.47 & 4.21 & $-4.243^{* *}$ & .000 \\
\cline { 2 - 6 } & Q2 & 3.45 & 4.13 & $-3.246^{* *}$ & .002 \\
\cline { 2 - 6 } & Q3 & 4.18 & 4.14 & .464 & .612 \\
\cline { 2 - 6 } & Q4 & 4.17 & 4.21 & -1.083 & .263 \\
\hline
\end{tabular}

Note: $* * \mathrm{p}<0.01$

Based on the results in Table 3, there are significant differences between the two groups of test samples in Q1 and Q2. This also shows that the optimization group students have a higher cognition of English situation understanding and knowledge construction significantly than the control group, which implies that the video teaching content after image optimization has a positive effect on improving students' situation understanding. However, there is no significant difference $(p>0.05)$ between the two groups of test samples in Q3 and Q4, which also shows that the video teaching content after image optimization has an insignificant effect on two items, and thus on students' situation understanding.

Students' classroom interaction: In the analysis of students' classroom interaction, the item indicators are refined, and the analysis contents are set to 4 indicators, i.e. Q5 (communication and interaction), Q6 (English classroom learning interest), Q7 (English learning desire), Q8 (improvement of learning effect). The independent sample $\mathrm{T}$ test results of the control sample in student classroom interaction dimension are shown in Table 4. 
Table 4. Comparison in students' classroom interaction dimension

\begin{tabular}{|c|c|c|c|c|c|}
\hline \multirow{2}{*}{ Dimension content } & \multirow{2}{*}{ Indicator } & Control group & Opti. group & \multicolumn{2}{|c|}{ T-TEST } \\
\cline { 3 - 6 } & & Mean & Mean & T-value & Sig \\
\hline \multirow{3}{*}{ Students' classroom interaction } & Q5 & 3.42 & 4.43 & .000 & 1.000 \\
\cline { 2 - 6 } & Q6 & 3.86 & 3.91 & -.272 & .764 \\
\cline { 2 - 6 } & Q7 & 3.69 & 3.72 & -.127 & .892 \\
\cline { 2 - 6 } & Q8 & 3.18 & 3.42 & -1.136 & .267 \\
\hline
\end{tabular}

Based on the results in Table 4, it can be found that the student classroom interaction dimension has no significant difference $(p>0.05)$ between the two groups in $Q 5$, Q6, Q7, and Q8, which also explains that during the English education, the optimization of video images does not have a significantly positive effect on these four indicators. However, in the means of the four indicators Q5, Q6, Q7, and Q8, the optimization group is higher than the control group, which also shows that compared with the control group, the optimization group can more effectively increase the communication and interaction between students during the learning process by the optimized video image materials, and the more optimized images can render more clear learning content and scope for the students. However, the mean values in this dimension are generally not high, which also presents that image optimization is not sufficient to improve students' cognition of classroom interaction.

Students' self-construction: In the analysis of students' self-construction, the item indicators are refined, and the analysis contents are set to 3 indicators, i.e. Q9 (integration of English listening, speaking, reading and writing), Q10 (self-correction), Q11 (memory of English classroom learning). The independent sample T test results of control samples in the students' self-construction dimension are shown in Table 5.

Based on the results in Table 5, there are significant differences between the two groups in Q9 and Q11, which also implies that optimization group has a significantly higher cognition of Q9 and Q11 than control group. This also illustrates that the video teaching content after image optimization has a positive effect on improving students' self-construction. On the self-correction indicator, there is no significant difference $(p>0.05)$ between the two groups of test samples, which also shows that the video teaching content after image optimization has no significant effect on the selfcorrection of students.

Table 5. Comparison in students' self-construction dimension

\begin{tabular}{|c|c|c|c|c|c|}
\hline \multirow{2}{*}{ Dimension content } & \multirow{2}{*}{ Indicator } & Control group & Opti. group & \multicolumn{2}{|c|}{ T-TEST } \\
\cline { 3 - 6 } & & Mean & Mean & T Value & Sig \\
\hline \multirow{2}{*}{ Students' situational understanding } & Q9 & 3.57 & 4.23 & $-4.162^{* *}$ & .000 \\
\cline { 2 - 6 } & Q10 & 4.21 & 4.32 & -1.045 & .244 \\
\hline & Q11 & 3.64 & 4.27 & $-3.168^{* *}$ & .002 \\
\hline
\end{tabular}

Note: $* * \mathrm{p}<0.01$

The above analysis shows that the optimization of teaching video images can improve students' situational cognition of the English education to a certain extent, thereby achieving the elevation of students' situational understanding, classroom interaction, and self-construction and other capabilities, thus enhancing students' in- 
teraction and interest in learning, and playing a significant effect on students in the basic English courses.

\section{Conclusion}

Situational cognition can help students to self-construction of knowledge to a large extent. Due to lack of situational cognition capacity in college English education, the image block gain optimization is underlying to study the validity of situational cognition in college English education. The empirical findings show that the image block gain optimization can effectively improve the construction of situational cognition of English in college education. This study tries to put forward the new useful ideas for the development of computer science and college English education in China, thus giving a great push to it.

\section{Acknowledgement}

Teaching Reform Project in Henan Province: 2017SJGLX263.Situational Cognition of College English Education Based on Image Block Gain Optimization in Pseudo-haze State.

\section{$6 \quad$ Reference}

[1] Park, B., Flowerday, T., Brünken, R. (2015). Cognitive and affective effects of seductive details in multimedia learning. Computers in Human Behavior, 44(3): 267-278. https://doi. org/10.1016/j.chb.2014.10.061

[2] Guan, X., Wang, D., Zhang, R. (2012). A Study on Experiential Translation Teaching under Multimedia Network Environment. Theory and Practice in Language Studies, 2(9): 1835-1840. https://doi.org/10.4304/tpls.2.9.1835-1840

[3] Walls, M. (2016). Development of Multiple Intelligence Theory and Situational Education. Making as a didactic process: Situated cognition and the chaîne opératoire. Quaternary International, 405: 21-30. https://doi.org/10.1016/j.quaint.2015.03.005

[4] Compton, P. (2013). Situated cognition and knowledge acquisition research. International Journal of Human - Computer Studies, 71(2): 184-190. https://doi.org/10.1016/j.ijhcs. 2012.10.002

[5] Kong, Y. (2018). A Study of the Current Situation and Countermeasures of Medical English Talents Training Based on KAQ Education Mode. Theory and Practice in Language Studies, 8(6): 694-701. https://doi.org/10.17507/tpls.0806.21

[6] Toh, G. (2016). Academic Writing in a Japanese Situation: Drawing on the Design Perspective towards an Affirmation of English as a Lingua Franca. Englishes in Practice, 3(2): 29-54. https://doi.org/10.1515/eip-2016-0002

[7] Gupta, H., Sharma, K. K., Joshi, S. D. (2015). Resource Efficient FPGA Implementation of Adaptive Image Enhancement Algorithms. IETE Journal of Research, 61(4): 429-439. https://doi.org/10.1080/03772063.2015.1009397

[8] Zuiderveld, K. (1994). Contrast limited adaptive histogram equalization. San Diego: Academic Press Inc: 474-485. https://doi.org/10.1016/b978-0-12-336156-1.50061-6 
[9] Land, E. H. (1983). Recent advances in retinex theory and some implications for cortical computations:color vision and the natural image. Proceedings of the National Academy of Sciences, 80(16): 5163-5169. https://doi.org/10.1073/pnas.80.16.5163

[10] Jobson, D. J., Rahman, Z., Woodell, G. A. (1997). Properties and performance of a center/surround retinex. IEEE transactions on image processing, 6(3): 451-462. https://doi. org/10.1109/83.557356

[11] He, K., Sun, J., Tang, X. (2011). Single image haze removal using dark channel prior. IEEE transactions on pattern analysis and machine intelligence, 33(12): $2341-2353$. https://doi.org/10.1109/tpami.2010.168

[12] Li, Y., Constantin, C., du Mouza, C. (2017). A block-based edge-partitionning for random walks algorithms in large social graphs, Ingénierie des Systèmes d'Information, 22(3), 89113. https://doi.org/10.3166/isi.22.3.89-113

[13] Zhao, H.H., Rosin, P.L., Lai, Y.K., Zheng, J.H., Wang, Y.N. (2020). Adaptive Block Compressive Sensing for Noisy Images, Studies in Computational Intelligence, 810, 389399. https://doi.org/10.1007/978-3-030-04946-1_38

[14] Reyes, M.G., Neuhoff, D.L., Pappas, T.N. (2020). MAP Interpolation of an Ising Image Blockf, Advances in Intelligent Systems and Computing, 943, 237-256

[15] Tian, S.Q. (2017). Improved electronic image stabilisation based on image Mosaic and Grey Projection, Review of Computer Engineering Studies, 4(4), 108-112. https://doi.org/ 10.18280/rces.040402

[16] Li, P., Yang, C.-N., Tang, D., Ma, J. (2020). Sharing More Information in Visual Cryptography Scheme with Block Expansion, Advances in Intelligent Systems and Computing, 895, 849-8574. https://doi.org/10.1007/978-3-030-16946-6_69

[17] Liang, H., Zhao, S. (2020). Salt and Pepper Noise Suppression for Medical Image by Using Non-local Homogenous Information, Studies in Computational Intelligence, 810, 189199. https://doi.org/10.1007/978-3-030-04946-1_19

[18] Roy, A., Dixit, R., Naskar, R., Chakraborty, R.S. (2020). Copy-Move Forgery Detection Exploiting Statistical Image Features, Studies in Computational Intelligence, 755, 57-64. https://doi.org/10.1007/978-981-10-7644-2_4

[19] Paul, S., Dasgupta, P., Kr, N.P., Chaudhuri, A. (2017). Secured image encryption scheme based on DNA encoding and chaotic map, Review of Computer Engineering Studies, 4(2), 70-75. https://doi.org/10.18280/rces.040206

[20] Elbeltagy, A.E.H.M., Youssef, A.M., Bayoumy, A.M., Elhalwagy, Y.Z. (2018). Fixed ground-target tracking control of satellites using a nonlinear model predictive control, Mathematical Modelling of Engineering Problems, 5(1), 11-20. https://doi.org/10.18280/ mmep.050102

[21] Bi, X., Shi, X., Zhang, Z. (2019). Cognitive machine learning model for network information safety, Safety Science, 118, 435-441. https://doi.org/10.1016/j.ssci.2019.05.032

[22] Pedersen, I., Lee Solevåg, A., Solberg, M.T. (2019). Simulation-Based Training Promotes Higher Levels of Cognitive Control in Acute and Unforeseen Situations, Clinical Simulation in Nursing, 34, 6-15. https://doi.org/10.1016/j.ecns.2019.05.003

[23] Liu, Y., Wang, S., Jie, X. (2019). Experiential Honeymoon Tourism Study from Perspective of Embodied Cognition, 5th International Conference on Information Management, ICIM 2019, 8714675, 327-331. https://doi.org/10.1109/infoman.2019.8714675

[24] Choraś, M., Kozik, R., Puchalski, D., Renk, R. (2019). Increasing product owners' cognition and decision-making capabilities by data analysis approach, Cognition, Technology and Work, 21(2), 191-200. https://doi.org/10.1007/s10111-018-0494-y

[25] Lieberman, M.D., Straccia, M.A., Meyer, M.L., Du, M., Tan, K.M. (2019). Social, self, (situational), and affective processes in medial prefrontal cortex (MPFC): Causal, multi- 
Paper - Situational Cognition of College English Education Based on Image Block Gain Optimization ..

variate, and reverse inference evidence, Neuroscience and Biobehavioral Reviews, 99, 311-328. https://doi.org/10.1016/j.neubiorev.2018.12.021

\section{$7 \quad$ Author}

Hongli Lou received the B.A. degree in language and literature from Henan Polytechnic University, China, in 2008, the Master degree in education from Bohai University, China, in 2011, and now is the dean of Academic Affair Office of Henan Polytechnic University. His current research interests focus on English teaching, higher education management and educational information technology.

Article submitted 2019-07-03. Resubmitted 2019-08-18. Final acceptance 2019-08-19. Final version published as submitted by the authors. 